\title{
AN MCDM APPROACH FOR PERSONNEL SELECTION USING THE COCOSO METHOD
}

\author{
Milica POPOVIĆ ${ }^{*}$ \\ ${ }^{1}$ Faculty of Applied Management, Economics and Finance, University Business Academy in Novi Sad, \\ Jevrejska 24, Belgrade, Serbia, milica.popovic.edu@gmail.com
}

\begin{abstract}
Candidate selection has a direct impact on the quality of a company's human resources department, so it's an essential activity for public and private companies alike. Various ways have been created to assist and make it easier for organizations to select the best candidate, specifically the right people to do specific roles. As a result, the purpose of this study is to propose the use of multi-criteria decisionmaking techniques in personnel selection. Therefore, for the determination of the weights of the criteria will be employed the SWARA method, whereas, for the ranking of the alternatives, i.e. selection of the best candidate, a CoCoSo method will be applied.
\end{abstract}

Keywords: personnel selection, HRM, MCDM, SWARA, CoCoSo.

Original scientific paper

Received: 10.11 .2021

Accepted: 26.11.2021

Available online: 26.11 .2021

\section{Introduction}

In the last two decades, all the efforts of theorists have mainly focused on the practice of human resource management (HRM). The state of well-being and job satisfaction have become an exceptional priority for managers and human resource managers, given the fact that human capital is the most important part of any company and that with its help organizational goals can be achieved.

Currently, companies are facing increasing competition, which requires managers to constantly find new ways to optimize their basic organizational resources, i.e. human resources, where in increasingly dynamic business conditions, human resources are considered a key success factor in implementing company policies, practices and strengthening the performance of the organization. Moreover, human resources are an important factor in the performance of an organization and represent the basis for achieving and maintaining a competitive advantage (Mousa \& Othman, 2020). An example of referencing in the text of the paper:

Recruitment is one of the activities of human resource management. According to Cooper and Robertson in their research (Robertson \& Cooper, 2015; Cooper \& Robertson, 1995), human resource managers have long studied and proposed different methods of measuring human

${ }^{*}$ Corresponding author 
characteristics, in order to better predict the future work performance of candidates. Of course, the goal is to hire the most appropriate and competent candidate for a particular job.

Personnel recruitment can be most simply viewed as a process / activity of attracting competent and qualified candidates in the number that will enable the organization to select the best candidates to fill vacancies (Nikolaou \& Oostrom, 2015). Consequently, recruitment is a process of identifying and attracting employees.

The recruitment process logically follows the recruitment process. Personnel selection is a process used for the final recruitment of candidates. Although the term can be applied to all aspects of the process, the most common meaning focuses on personnel selection. The selection of personnel aims to select from the pool of the candidates, those who will have the greatest success in the future. In addition, it is necessary to select candidates who will meet the requirements of the job in accordance with the job description and the criteria that a particular job requires. Also, the candidate is expected to get involved in the work process as soon as possible and to have the potential for fast and high professional development (Štangl-Šušnjar et al., 2017; Avakumović, 2019).

Therefore, the aim of this paper is to propose the use of multi-criteria decision-making methods in personnel selection. For the determination of the weights of the criteria will be employed the SWARA method, whereas, for the ranking of the alternatives, i.e. selection of the best candidate, a CoCoSo method will be applied.

\section{Literature review}

Multi-criteria decision-making methods have also found their application in the field of human resource management. In order to select the optimal candidate to fill the appropriate position in the organization, the authors applied different methods of multi-criteria decision making. Some of the relevant research will be presented in the following lines.

To improve employee performance, Albayrak \& Erensal (2004) proposed the application of the Analytical Hierarchical Process (AHP). The AHP method has been applied to structure and clarify the relationships and significance between employee performance and applied management styles. The final results of the conducted analysis indicated that it is in accordance with the existing conditions, and in order to improve the performance of employees, it is most appropriate to apply value management. The authors Gürbüz and Albayrak (2014) proposed the application of a model based on ANP (Analytical Network Process) and CI (Choquet Integral) methods with the same goal. Research has suggested that neglecting interactions can lead to erroneous conclusions.

Dağdeviren (2010) applied a hybrid MCDM model in the candidate selection process. This hybrid model is based on ANP method and modified TOPSIS methods. As stated in the paper, the management of the company on whose example the applicability of the model was demonstrated, have stated that the application of the model and the obtained results are satisfactory and that it is possible to implement them in their employee selection process.

The SAW (Simple Additive Weighting) method, which is a well-known and frequently used method, has also been applied in the case of selecting an adequate candidate (Afshari et al., 2010). Based on 7 criteria, 5 candidates were evaluated for employment in a telecommunications company in Iran. To simplify the application of the proposed model, the authors proposed the application of simple software such as MS Excel. The disadvantage of this research is reflected in the failure to include the uncertainty of the environment in which decision-making is realized. 
Making optimal decisions in the field of evaluation and selection of candidates can be achieved by applying the SWARA and ARAS (Additive Ratio Assessment method) methods (Karabašević et al., 2015). The proposed approach was applied in the evaluation of candidates for the position of sales manager. It was chosen from 4 candidates, based on 6 criteria, and the evaluation was carried out by three decision makers, more precisely human resources managers. The SWARA method was used to define the significance of the evaluation criteria, and the ARAS method was used for the final evaluation and ranking of the candidates.

Zavadskas et al. (2012) proposed the application of the AHP method, expert evaluation and the ARAS method in the selection of an appropriate project manager in the field of construction. The obtained results confirmed that the combination of the mentioned MCDM methods enabled the successful solution of the given problem, i.e. the selection of the optimal candidate. The proposed model is not only applicable in scientific terms, but also in practical ones. It allows investors to evaluate candidates based on a number of criteria. In addition to the area of human resources, the proposed model is applicable in other areas of business. Finally, the obtained results confirm that the proposed model represents a very useful decision support.

An approach based on the Entropy and KEMIRA (KEmeny Median Indicator Ranks Accordance) methods has also been shown to be useful in the evaluation and selection of an adequate candidate (Krylovas et al., 2017). The criteria were divided into 3 groups, and each group contained 11 criteria. The evaluation included 87 randomly selected respondents aged 2123 years. The entropy method was used to define the priority of the criteria in each group separately, while KEMIRA was applied to determine the final weights of the criteria. The results confirmed the applicability of the KEMIRA method when a large number of criteria are present.

Theorists in the field of multi-criteria decision-making have proposed appropriate extensions of methods by introducing the fuzzy logic and grey numbers, all in order to obtain the most relevant results in the process of evaluation and selection of candidates.

Karsak (2001) developed a decision-making framework based on ideal and anti-ideal solutions in the fuzzy environment. In this way, data in the form of linguistic variables, triangular fuzzy numbers are included in the process of selecting the appropriate candidate. Later, Dursun and Karsak (2010) proposed the application of a multi-criteria decision-making fuzzy based on the information fusion fuzzy, a 2-tuple linguistic representation of the model, and the TOPSIS method (Technique for Order Preference by Similarity to Ideal Solution). In addition to enabling the evaluation of information based on a linguistic and numerical scale, this model allows managers to manage heterogeneous information.

In order to reduce subjectivity in the decision-making process when selecting candidates, the application of the intuitionistic fuzzy MCDM method with Grey Relational Analysis (GRA) has been proposed (Zhang \& Liu, 2011). The IFWA operator was used to aggregate individual decision makers 'attitudes into a common position, while the intuitionistic fuzzy entropy method was used to obtain criteria weights. Finally, the final ranking of alternatives was performed using the GRA method.

With the aim of correctly defining the importance of the criteria for the selection of a qualified manager in a health institution and the selection of an appropriate candidate, in the work of the author Uslu et al. (2021) proposed the application of the fuzzy AHP and MULTIMOORA methods. 8 candidates were evaluated in relation to 12 criteria. The MULTIMOORA method was applied based on the results of the interviews and the evaluation of the commission to which the evaluation was entrusted. 
In the previous lines, only a part of the research related to the examination of the possibility of applying the methods and models of multi-criteria decision-making in the field of human resources management and candidate selection is presented.

\section{The CoCoSo method}

A relatively new CoCoSo method (Combined Compromise Solution), developed by Jazdani et al. (Yazdani et al., 2019a), is based on the integration of simple additive weighting (SAW) and the exponentially weighted product model (MEP). The essence of this method lies in combining compromise perspectives, which ultimately reconciles the evaluation criteria, which are often conflicting. The CoCoSo method provides an overview of possible compromise solutions available to the decision maker. There are many authors that are solving a variety of problems with the CoCoSo method, such as Bagal et al. (2021); Peng et al. (2021); Peng \& Luo (2021); Ulutaş et al. (2021); Deveci et al. (2021); Ecer (2021); Torkayesh et al. (2021a; b); Stanujkic et al. (2020); and Wen et al. (2019).

The calculation procedure of the CoCoSo method can be illustrated by applying the following steps (Yazdani et al., 2019):

Step 1. Defining the initial decision matrix.

Step 2. Normalization of criteria values.

In the case of beneficial criteria, normalization is performed as follows:

$$
r_{i j}=\frac{x_{i j}-\min _{i} x_{i j}}{\max _{i} x_{i j}-\min _{i} x_{i j}} .
$$

where $r_{i j}$ is a normalized rating of the alternative $i$ in relation to the criterion $j$, and $x_{i j}$ denotes rating of the alternative $i$ in relation to the criterion $j$.

In the case of nonbeneficial criteria, normalization is performed as follows:

$$
r_{i j}=\frac{\max _{i} x_{i j}-x_{i j}}{\max _{i} x_{i j}-\min _{i} x_{i j}} .
$$

Step 3. Application of the CoCoSo method based on the integration of SAW and MEP approaches, as follows:

$$
\begin{gathered}
S_{i}=\sum_{j=1}^{n} r_{i j} w_{j}, \\
\mathrm{P}_{\mathrm{i}}=\sum_{\mathrm{j}=1}^{\mathrm{n}} \mathrm{r}_{\mathrm{ij}} .
\end{gathered}
$$

where $S i$ and $P i$ represent the sum of weight-comparable sequences and weight-multiplied comparable sequences of the alternative $i$, respectively, and $w_{j}$ denotes weights of the criterion $j$,

Step 4. Ranking of considered alternatives. For ranking purposes, the CoCoSo method uses a relative performance score $k_{\text {, }}$ which is calculated based on three aggregate estimated results $k_{i a}$, $k_{i b}$ и $k_{i c}$, as follows:

$$
k_{i}=\frac{1}{3}\left(k_{i a}+k_{i b}+k_{i c}\right)+\left(k_{i a} k_{i b} k_{i c}\right)^{\frac{1}{3}}
$$

with:

$$
\begin{gathered}
k_{i a}=\frac{S_{i}+P_{i}}{\sum_{i=1}^{m}\left(S_{i}+P_{i}\right)^{\prime}} \\
k_{i b}=\frac{S_{i}}{\operatorname{mins}_{i}}+\frac{P_{i}}{\operatorname{minP}_{i}^{\prime}}, \\
k_{i c}=\frac{\lambda S_{i}+(1-\lambda) P_{i}}{\lambda \max _{i} \operatorname{si}+(1-\lambda) \max _{i} P_{i}} .
\end{gathered}
$$




\section{Application of the CoCoSo method for the ranking of alternatives}

In this part of the paper, the segment related to ranking of alternatives based on the CoCoSo method is presented. In this study a total of 10 decision-makers have evaluated 30 candidates.

Based on the investigated literature the following set of criteria was chosen: $C_{1}$ - Relevant previous work experience; $C_{2}$ - Education; $C_{3}$ - Interview readiness; $C_{4}$ - Interpersonal skills; $C_{5}-$ Communication and presentation skills, and $C_{6}-$ Computer skills.

In the continuation of the paper, the obtained weights of evaluation criteria of all respondents for the stated criteria are presented. The relative meanings of the criteria obtained from the first respondent are shown in Table 1. Table 1 also shows the procedure for calculating weights using the SWARA method, as well as the calculated weights of the criteria.

Table 1 shows the group weights that are obtained by using the SWARA method.

Table 1. Group criteria weights obtained by using the SWARA method

\begin{tabular}{l|l|c|c|c|c}
\hline \multicolumn{1}{c}{ Criteria } & $s_{j}$ & $k_{j}$ & $q_{j}$ & $w_{j}$ \\
\hline$C_{1}$ & Relevant previous work experience & & 1 & 1 & 0.22 \\
\hline$C_{2}$ & Education & 0.09 & 1.09 & 0.92 & 0.21 \\
\hline$C_{3}$ & Interview readiness & 0.16 & 1.16 & 0.79 & 0.18 \\
\hline$C_{4}$ & Interpersonal skills & 0.21 & 1.21 & 0.65 & 0.15 \\
\hline$C_{5}$ & Communication and presentation skills & 0.14 & 1.14 & 0.57 & 0.13 \\
\hline$C_{6}$ & Computer skills & 0.08 & 1.08 & 0.53 & 0.12 \\
\hline
\end{tabular}

The evaluation procedure of all 30 candidates using the CoCoSo method is shown in Tables 56 to 60 . The normalized decision matrix, the weighted normalized decision matrix, as well as the exponential weighted normalized decision matrix are shown in the tables 2-4.

Table 2. Normalized decision matrix

\begin{tabular}{c|c|c|c|c|c|c}
\hline $\begin{array}{c}\text { Criteria } \\
\text { Alternatives }\end{array}$ & $C_{1}$ & $C_{2}$ & $C_{3}$ & $C_{4}$ & $C_{5}$ & $C_{6}$ \\
\hline$w_{i}$ & 0.22 & 0.21 & 0.18 & 0.15 & 0.13 & 0.12 \\
\hline$A_{1}$ & 0.97 & 0.76 & 0.71 & 0.72 & 0.70 & 0.71 \\
\hline$A_{2}$ & 0.94 & 0.95 & 0.49 & 0.67 & 0.52 & 0.69 \\
\hline$A_{3}$ & 0.45 & 0.81 & 0.31 & 0.44 & 0.70 & 1.00 \\
\hline$A_{4}$ & 0.88 & 0.97 & 0.43 & 1.00 & 0.61 & 0.26 \\
\hline$A_{5}$ & 0.70 & 0.65 & 0.46 & 0.56 & 0.45 & 0.74 \\
\hline$A_{6}$ & 1.00 & 0.73 & 0.71 & 1.00 & 1.00 & 0.71 \\
\hline$A_{7}$ & 0.09 & 0.22 & 0.66 & 0.50 & 0.03 & 0.09 \\
\hline$A_{8}$ & 1.00 & 0.24 & 0.00 & 1.00 & 1.00 & 0.71 \\
\hline$A_{9}$ & 0.06 & 0.97 & 0.20 & 1.00 & 0.73 & 0.20 \\
\hline$A_{10}$ & 1.00 & 0.46 & 0.14 & 0.00 & 1.00 & 0.14 \\
\hline$A_{11}$ & 0.18 & 0.30 & 0.94 & 0.33 & 1.00 & 0.14 \\
\hline$A_{12}$ & 0.91 & 0.70 & 0.00 & 0.28 & 1.00 & 0.49 \\
\hline$A_{13}$ & 0.70 & 0.22 & 0.06 & 0.19 & 0.39 & 1.00 \\
\hline$A_{14}$ & 0.73 & 0.19 & 0.11 & 0.75 & 0.73 & 0.71 \\
\hline$A_{15}$ & 0.30 & 0.68 & 0.26 & 1.00 & 0.79 & 0.17 \\
\hline$A_{16}$ & 1.00 & 0.73 & 0.17 & 0.44 & 0.39 & 0.43 \\
\hline$A_{17}$ & 0.00 & 0.49 & 0.97 & 0.14 & 0.73 & 0.20 \\
\hline$A_{18}$ & 1.00 & 0.08 & 1.00 & 0.19 & 0.12 & 1.00 \\
\hline$A_{19}$ & 0.73 & 1.00 & 0.71 & 0.72 & 0.00 & 0.43 \\
\hline$A_{20}$ & 0.12 & 0.30 & 0.26 & 0.25 & 0.42 & 0.46 \\
\hline$A_{21}$ & 1.00 & 1.00 & 0.17 & 1.00 & 1.00 & 0.71 \\
\hline$A_{22}$ & 0.36 & 0.59 & 0.74 & 0.81 & 0.45 & 0.89 \\
\hline$A_{23}$ & 0.33 & 0.68 & 0.63 & 0.44 & 0.58 & 0.34 \\
\hline$A_{24}$ & 0.27 & 0.51 & 0.26 & 1.00 & 1.00 & 0.94 \\
\hline$A_{25}$ & 0.45 & 0.49 & 0.97 & 0.25 & 0.18 & 0.97 \\
\hline$A_{26}$ & 1.00 & 0.92 & 0.89 & 1.00 & 0.21 & 0.71 \\
\hline & & & & & & \\
\hline
\end{tabular}




\begin{tabular}{c|c|c|c|c|c|c}
\hline$A_{27}$ & 0.61 & 0.49 & 0.57 & 0.86 & 0.97 & 0.71 \\
\hline$A_{28}$ & 0.42 & 0.27 & 0.43 & 0.78 & 0.52 & 0.17 \\
\hline$A_{29}$ & 0.39 & 0.19 & 0.43 & 0.72 & 0.39 & 0.14 \\
\hline$A_{30}$ & 0.45 & 0.00 & 0.37 & 0.75 & 0.73 & 0.00 \\
\hline
\end{tabular}

Table 3. Weighted normalized decision matrix

\begin{tabular}{|c|c|c|c|c|c|c|}
\hline $\begin{array}{c}\text { Criteria } \\
\text { Alternatives }\end{array}$ & $C_{1}$ & $C_{2}$ & $C_{3}$ & $C_{4}$ & $C_{5}$ & $C_{6}$ \\
\hline$A_{1}$ & 0.22 & 0.16 & 0.13 & 0.11 & 0.09 & 0.08 \\
\hline$A_{2}$ & 0.21 & 0.19 & 0.09 & 0.10 & 0.07 & 0.08 \\
\hline$A_{3}$ & 0.10 & 0.17 & 0.06 & 0.07 & 0.09 & 0.12 \\
\hline$A_{4}$ & 0.20 & 0.20 & 0.08 & 0.15 & 0.08 & 0.03 \\
\hline$A_{5}$ & 0.16 & 0.13 & 0.08 & 0.08 & 0.06 & 0.09 \\
\hline$A_{6}$ & 0.22 & 0.15 & 0.13 & 0.15 & 0.13 & 0.08 \\
\hline$A_{7}$ & 0.02 & 0.04 & 0.12 & 0.07 & 0.00 & 0.01 \\
\hline$A_{8}$ & 0.22 & 0.05 & 0.00 & 0.15 & 0.13 & 0.08 \\
\hline$A_{9}$ & 0.01 & 0.20 & 0.04 & 0.15 & 0.09 & 0.02 \\
\hline$A_{10}$ & 0.22 & 0.09 & 0.03 & 0.00 & 0.13 & 0.02 \\
\hline$A_{11}$ & 0.04 & 0.06 & 0.17 & 0.05 & 0.13 & 0.02 \\
\hline$A_{12}$ & 0.20 & 0.14 & 0.00 & 0.04 & 0.13 & 0.06 \\
\hline$A_{13}$ & 0.16 & 0.04 & 0.01 & 0.03 & 0.05 & 0.12 \\
\hline$A_{14}$ & 0.16 & 0.04 & 0.02 & 0.11 & 0.09 & 0.08 \\
\hline$A_{15}$ & 0.07 & 0.14 & 0.05 & 0.15 & 0.10 & 0.02 \\
\hline$A_{16}$ & 0.22 & 0.15 & 0.03 & 0.07 & 0.05 & 0.05 \\
\hline$A_{17}$ & 0.00 & 0.10 & 0.17 & 0.02 & 0.09 & 0.02 \\
\hline$A_{18}$ & 0.22 & 0.02 & 0.18 & 0.03 & 0.02 & 0.12 \\
\hline$A_{19}$ & 0.16 & 0.21 & 0.13 & 0.11 & 0.00 & 0.05 \\
\hline$A_{20}$ & 0.03 & 0.06 & 0.05 & 0.04 & 0.05 & 0.05 \\
\hline$A_{21}$ & 0.22 & 0.21 & 0.03 & 0.15 & 0.13 & 0.08 \\
\hline$A_{22}$ & 0.08 & 0.12 & 0.13 & 0.12 & 0.06 & 0.11 \\
\hline$A_{23}$ & 0.07 & 0.14 & 0.11 & 0.07 & 0.07 & 0.04 \\
\hline$A_{24}$ & 0.06 & 0.11 & 0.05 & 0.15 & 0.13 & 0.11 \\
\hline$A_{25}$ & 0.10 & 0.10 & 0.17 & 0.04 & 0.02 & 0.12 \\
\hline$A_{26}$ & 0.22 & 0.19 & 0.16 & 0.15 & 0.03 & 0.08 \\
\hline$A_{27}$ & 0.14 & 0.10 & 0.10 & 0.13 & 0.12 & 0.08 \\
\hline$A_{28}$ & 0.09 & 0.06 & 0.08 & 0.11 & 0.07 & 0.02 \\
\hline$A_{29}$ & 0.09 & 0.04 & 0.08 & 0.11 & 0.05 & 0.02 \\
\hline$A_{30}$ & 0.10 & 0.00 & 0.07 & 0.11 & 0.09 & 0.00 \\
\hline
\end{tabular}

Table 4. Exponential weighted normalized decision matrix

\begin{tabular}{c|c|c|c|c|c|c}
\hline $\begin{array}{c}\text { Criteria } \\
\text { Alternatives }\end{array}$ & $C_{1}$ & $C_{2}$ & $C_{3}$ & $C_{4}$ & $C_{5}$ & $C_{6}$ \\
\hline$A_{1}$ & 0.99 & 0.94 & 0.94 & 0.95 & 0.95 & 0.96 \\
\hline$A_{2}$ & 0.99 & 0.99 & 0.88 & 0.94 & 0.92 & 0.96 \\
\hline$A_{3}$ & 0.84 & 0.96 & 0.81 & 0.89 & 0.95 & 1.00 \\
\hline$A_{4}$ & 0.97 & 0.99 & 0.86 & 1.00 & 0.94 & 0.85 \\
\hline$A_{5}$ & 0.92 & 0.91 & 0.87 & 0.92 & 0.90 & 0.97 \\
\hline$A_{6}$ & 1.00 & 0.94 & 0.94 & 1.00 & 1.00 & 0.96 \\
\hline$A_{7}$ & 0.58 & 0.73 & 0.93 & 0.90 & 0.64 & 0.75 \\
\hline$A_{8}$ & 1.00 & 0.75 & 0.00 & 1.00 & 1.00 & 0.96 \\
\hline$A_{9}$ & 0.53 & 0.99 & 0.75 & 1.00 & 0.96 & 0.83 \\
\hline$A_{10}$ & 1.00 & 0.85 & 0.71 & 0.00 & 1.00 & 0.79 \\
\hline$A_{11}$ & 0.68 & 0.78 & 0.99 & 0.85 & 1.00 & 0.79 \\
\hline
\end{tabular}




\begin{tabular}{l|l|l|l|l|l|l}
\hline$A_{12}$ & 0.98 & 0.93 & 0.00 & 0.83 & 1.00 & 0.92 \\
\hline$A_{13}$ & 0.92 & 0.73 & 0.60 & 0.79 & 0.89 & 1.00 \\
\hline$A_{14}$ & 0.93 & 0.71 & 0.68 & 0.96 & 0.96 & 0.96 \\
\hline$A_{15}$ & 0.77 & 0.92 & 0.79 & 1.00 & 0.97 & 0.81 \\
\hline$A_{16}$ & 1.00 & 0.94 & 0.73 & 0.89 & 0.89 & 0.90 \\
\hline$A_{17}$ & 0.00 & 0.86 & 0.99 & 0.75 & 0.96 & 0.83 \\
\hline$A_{18}$ & 1.00 & 0.60 & 1.00 & 0.79 & 0.76 & 1.00 \\
\hline$A_{19}$ & 0.93 & 1.00 & 0.94 & 0.95 & 0.00 & 0.90 \\
\hline$A_{20}$ & 0.62 & 0.78 & 0.79 & 0.82 & 0.90 & 0.91 \\
\hline$A_{21}$ & 1.00 & 1.00 & 0.73 & 1.00 & 1.00 & 0.96 \\
\hline$A_{22}$ & 0.80 & 0.90 & 0.95 & 0.97 & 0.90 & 0.99 \\
\hline$A_{23}$ & 0.78 & 0.92 & 0.92 & 0.89 & 0.93 & 0.88 \\
\hline$A_{24}$ & 0.75 & 0.87 & 0.79 & 1.00 & 1.00 & 0.99 \\
\hline$A_{25}$ & 0.84 & 0.86 & 0.99 & 0.82 & 0.80 & 1.00 \\
\hline$A_{26}$ & 1.00 & 0.98 & 0.98 & 1.00 & 0.82 & 0.96 \\
\hline$A_{27}$ & 0.89 & 0.86 & 0.91 & 0.98 & 1.00 & 0.96 \\
\hline$A_{28}$ & 0.83 & 0.76 & 0.86 & 0.96 & 0.92 & 0.81 \\
\hline$A_{29}$ & 0.81 & 0.71 & 0.86 & 0.95 & 0.89 & 0.79 \\
\hline$A_{30}$ & 0.84 & 0.00 & 0.84 & 0.96 & 0.96 & 0.00 \\
\hline & & & & & &
\end{tabular}

Based on the data from Tables 3 and 4, the values of $S_{i}$ and $P_{i}$ alternatives were calculated, which are shown in Table 5.

Table 5. Values of parameters $S_{i}$ and $P_{i}$

\begin{tabular}{|c|c|c|}
\hline & $S_{i}$ & $P_{i}$ \\
\hline$A_{1}$ & 0.78 & 5.75 \\
\hline$A_{2}$ & 0.74 & 5.67 \\
\hline$A_{3}$ & 0.60 & 5.45 \\
\hline$A_{4}$ & 0.73 & 5.62 \\
\hline$A_{5}$ & 0.60 & 5.49 \\
\hline$A_{6}$ & 0.86 & 5.84 \\
\hline$A_{7}$ & 0.27 & 4.53 \\
\hline$A 8$ & 0.63 & 4.71 \\
\hline$A 9$ & 0.51 & 5.07 \\
\hline$A_{10}$ & 0.49 & 4.35 \\
\hline$A_{11}$ & 0.46 & 5.10 \\
\hline$A_{12}$ & 0.57 & 4.66 \\
\hline$A_{13}$ & 0.41 & 4.93 \\
\hline$A_{14}$ & 0.51 & 5.20 \\
\hline$A_{15}$ & 0.52 & 5.26 \\
\hline$A_{16}$ & 0.57 & 5.35 \\
\hline$A_{17}$ & 0.41 & 4.39 \\
\hline$A_{18}$ & 0.58 & 5.15 \\
\hline$A_{19}$ & 0.65 & 4.73 \\
\hline$A_{20}$ & 0.28 & 4.81 \\
\hline$A_{21}$ & 0.82 & 5.69 \\
\hline$A_{22}$ & 0.62 & 5.50 \\
\hline$A_{23}$ & 0.50 & 5.33 \\
\hline$A_{24}$ & 0.60 & 5.40 \\
\hline$A_{25}$ & 0.55 & 5.31 \\
\hline$A_{26}$ & 0.83 & 5.74 \\
\hline$A_{27}$ & 0.67 & 5.60 \\
\hline
\end{tabular}




\begin{tabular}{c|c|c}
\hline$A_{28}$ & 0.43 & 5.14 \\
\hline$A_{29}$ & 0.38 & 5.02 \\
\hline$A_{30}$ & 0.37 & 3.60 \\
\hline sum & 16.93 & 154.38 \\
\hline min & 0.27 & 3.60 \\
\hline max & 0.86 & 5.84 \\
\hline
\end{tabular}

Based on value values $S_{i}$ and $P_{i}$, from previous table, the values of the coefficients Kia, Kib, and Kic, were calculated, which were used for the final ranking of alternatives using the CoCoSo method, as is shown in table 6.

Table 6. Calculation details obtained using the CoCoSo method

\begin{tabular}{|c|c|c|c|c|c|}
\hline $\begin{array}{c}\text { Criteria } \\
\text { Alternatives }\end{array}$ & Kia & $K i b$ & Kic & Ki & Rank \\
\hline$A_{1}$ & 0.04 & 4.50 & 0.97 & 2.39 & 4 \\
\hline$A_{2}$ & 0.04 & 4.32 & 0.96 & 2.31 & 5 \\
\hline$A_{3}$ & 0.04 & 3.74 & 0.90 & 2.05 & 10 \\
\hline$A_{4}$ & 0.04 & 4.27 & 0.95 & 2.28 & 6 \\
\hline$A_{5}$ & 0.04 & 3.76 & 0.91 & 2.06 & 9 \\
\hline$A_{6}$ & 0.04 & 4.83 & 1.00 & 2.53 & 1 \\
\hline$A_{7}$ & 0.03 & 2.26 & 0.72 & 1.36 & 29 \\
\hline$A_{8}$ & 0.03 & 3.67 & 0.80 & 1.95 & 16 \\
\hline$A_{9}$ & 0.03 & 3.32 & 0.83 & 1.84 & 21 \\
\hline$A_{10}$ & 0.03 & 3.03 & 0.72 & 1.66 & 24 \\
\hline$A_{11}$ & 0.03 & 3.14 & 0.83 & 1.77 & 22 \\
\hline$A_{12}$ & 0.03 & 3.43 & 0.78 & 1.85 & 20 \\
\hline$A_{13}$ & 0.03 & 2.89 & 0.80 & 1.65 & 25 \\
\hline$A_{14}$ & 0.03 & 3.35 & 0.85 & 1.87 & 19 \\
\hline$A_{15}$ & 0.03 & 3.40 & 0.86 & 1.89 & 17 \\
\hline$A_{16}$ & 0.03 & 3.61 & 0.88 & 1.99 & 12 \\
\hline$A_{17}$ & 0.03 & 2.75 & 0.72 & 1.54 & 27 \\
\hline$A_{18}$ & 0.03 & 3.59 & 0.85 & 1.96 & 14 \\
\hline$A_{19}$ & 0.03 & 3.74 & 0.80 & 1.98 & 13 \\
\hline$A_{20}$ & 0.03 & 2.38 & 0.76 & 1.43 & 28 \\
\hline$A_{21}$ & 0.04 & 4.63 & 0.97 & 2.44 & 3 \\
\hline$A_{22}$ & 0.04 & 3.83 & 0.91 & 2.09 & 8 \\
\hline$A_{23}$ & 0.03 & 3.36 & 0.87 & 1.88 & 18 \\
\hline$A_{24}$ & 0.04 & 3.73 & 0.90 & 2.04 & 11 \\
\hline$A_{25}$ & 0.03 & 3.52 & 0.87 & 1.95 & 15 \\
\hline$A_{26}$ & 0.04 & 4.68 & 0.98 & 2.46 & 2 \\
\hline$A_{27}$ & 0.04 & 4.06 & 0.94 & 2.19 & 7 \\
\hline$A_{28}$ & 0.03 & 3.02 & 0.83 & 1.73 & 23 \\
\hline$A_{29}$ & 0.03 & 2.80 & 0.80 & 1.62 & 26 \\
\hline$A_{30}$ & 0.02 & 2.38 & 0.59 & 1.32 & 30 \\
\hline
\end{tabular}

From Table 6 it can be seen that in the case of applying the CoCoSo method, the best ranked alternative is marked as $A_{1}$. 


\section{Conclusion}

The ability of modern organizations to maintain their competitive advantage is influenced by the current business environment. Without a doubt, an organization's human capital is the most crucial aspect in developing and preserving its competitive edge.

The inclusion of mathematical methods and models in the decision-making process, more precisely in the process of evaluation and selection of personnel, has enabled obtaining results relevant from a scientific aspect. The proposed approach based on the CoCoSo method is simple and understandable to the people from practice or managers who were involved in the evaluation process. The application of the proposed approach enables managers to make a decision on the selection of personnel in an efficient and effective way. The CoCoSo method, although recently proposed, has proven to be very useful and reliable.

The basic limitations of this paper are related to the application of crisp numbers that cannot fully respect and illustrate the uncertainty with which each decision-making process is associated. The reason for using crisp numbers lies in the fact that the intention was to propose such a simple model that would be easily understood by people in practice. The application of multi-criteria decision-making methods in everyday business is justified and desirable, because they enable more authoritative decisions and contribute to finding optimal solutions.

\section{References}

Afshari, A., Mojahed, M., \& Yusuff, R. M. (2010). Simple additive weighting approach to personnel selection problem. International Journal of Innovation, Management and Technology, 1(5), 511.

Albayrak, E., \& Erensal, Y. C. (2004). Using analytic hierarchy process (AHP) to improve human performance: An application of multiple criteria decision making problem. Journal of Intelligent Manufacturing, 15(4), 491-503.

Avakumović, J. (2019). HRM activities grouped in AMO model in the system of higher education. Ekonomski izazovi, 8(16), 90-99.

Bagal, D. K., Giri, A., Pattanaik, A. K., Jeet, S., Barua, A., \& Panda, S. N. (2021). MCDM Optimization of Characteristics in Resistance Spot Welding for Dissimilar Materials Utilizing Advanced Hybrid Taguchi Method-Coupled CoCoSo, EDAS and WASPAS Method. In Next Generation Materials and Processing Technologies (pp. 475-490). Springer, Singapore.

Cooper, D., \& Robertson, I. T. (1995). The psychology of personnel selection: A quality approach. Burns \& Oates.

Dağdeviren, M. (2010). A hybrid multi-criteria decision-making model for personnel selection in manufacturing systems. Journal of Intelligent manufacturing, 21(4), 451-460.

Deveci, M., Pamucar, D., \& Gokasar, I. (2021). Fuzzy Power Heronian function based CoCoSo method for the advantage prioritization of autonomous vehicles in real-time traffic management. Sustainable Cities and Society, 69, 102846.

Dursun, M., \& Karsak, E. E. (2010). Fuzzy MCDM approach for personnel selection. Expert Systems with Applications, 37, 4324-4330.

Ecer, F. (2021). A consolidated MCDM framework for performance assessment of battery electric vehicles based on ranking strategies. Renewable and Sustainable Energy Reviews, 143, 110916. 
Gürbüz, T., \& Albayrak, Y. E. (2014). An engineering approach to human resources performance evaluation: Hybrid MCDM application with interactions. Applied Soft Computing, 21, 365375.

Karabašević, D., Stanujkić, D., \& Urošević, S. (2015). The MCDM Model for Personnel Selection Based on SWARA and ARAS Methods. Management, 20(77).

Karsak, E. E. (2001). Personnel selection using a fuzzy MCDM approach based on ideal and anti-ideal solutions. In Multiple criteria decision making in the new millennium (pp. 393-402). Springer, Berlin, Heidelberg.

Krylovas, A., Dadelo, S., Kosareva, N., \& Zavadskas, E. K. (2017). Entropy-KEMIRA approach for MCDM problem solution in human resources selection task. International journal of information technology \& decision making, 16(05), 1183-1209.

Mousa, S. K., \& Othman, M. (2020). The impact of green human resource management practices on sustainable performance in healthcare organisations: A conceptual framework. Journal of Cleaner Production, 243, 118595.

Nikolaou, I., \& Oostrom, J. K. (Eds.). (2015). Employee recruitment, selection, and assessment: Contemporary issues for theory and practice. Psychology Press.

Peng, X., \& Luo, Z. (2021). Decision-making model for China's stock market bubble warning: the CoCoSo with picture fuzzy information. Artificial Intelligence Review, 1-23.

Peng, X., Krishankumar, R., \& Ravichandran, K. S. (2021). A novel interval-valued fuzzy soft decision-making method based on CoCoSo and CRITIC for intelligent healthcare management evaluation. Soft Computing, 25(6), 4213-4241.

Robertson, I. T., \& Cooper, C. (Eds.). (2015). Personnel psychology and human resources management: A reader for students and practitioners. John Wiley \& Sons.

Štang-Šušnjar, G., Slavić, A., Berber, N. (2017) Menadžment ljudskih resursa. Ekonomski fakultet, Subotica (In Serbian).

Stanujkic, D., Popovic, G., Zavadskas, E. K., Karabasevic, D., \& Binkyte-Veliene, A. (2020). Assessment of Progress towards Achieving Sustainable Development Goals of the "Agenda 2030" by Using the CoCoSo and the Shannon Entropy Methods: The Case of the EU Countries. Sustainability, 12(14), 5717.

Torkayesh, A. E., Ecer, F., Pamucar, D., \& Karamaşa, Ç. (2021b). Comparative assessment of social sustainability performance: Integrated data-driven weighting system and CoCoSo model. Sustainable Cities and Society, 71, 102975.

Torkayesh, A. E., Pamucar, D., Ecer, F., \& Chatterjee, P. (2021a). An integrated BWM-LBWACoCoSo framework for evaluation of healthcare sectors in Eastern Europe. Socio-Economic Planning Sciences, 101052.

Ulutaş, A., Popovic, G., Radanov, P., Stanujkic, D., \& Karabasevic, D. (2021). A new hybrid fuzzy PSI-PIPRECIA-CoCoSo MCDM based approach to solving the transportation company selection problem. Technological and Economic Development of Economy, 27(5), 1227-1249.

Uslu, Y. D., Yılmaz, E., \& Yiğit, P. (2021). Developing Qualified Personnel Selection Strategies Using MCDM Approach: A University Hospital Practice. In Strategic Outlook in Business and Finance Innovation: Multidimensional Policies for Emerging Economies. Emerald Publishing Limited. 
Wen, Z., Liao, H., Kazimieras Zavadskas, E., \& Al-Barakati, A. (2019). Selection third-party logistics service providers in supply chain finance by a hesitant fuzzy linguistic combined compromise solution method. Economic research-Ekonomska istraživanja, 32(1), 4033-4058.

Yazdani, M., Zarate, P., Zavadskas, E. K., \& Turskis, Z. (2019a). A Combined Compromise Solution (CoCoSo) method for multi-criteria decision-making problems. Management Decision, 57(9), 2501-2519.

Zavadskas, E. K., Vainiūnas, P., Turskis, Z., \& Tamošaitienė, J. (2012). Multiple criteria decision support system for assessment of projects managers in construction. International journal of information technology \& decision making, 11(02), 501-520.

Zhang, S. F., \& Liu, S. Y. (2011). A GRA-based intuitionistic fuzzy multi-criteria group decision making method for personnel selection. Expert Systems with Applications, 38(9), 1140111405.

(c) 2021 by the authors. Submitted for possible open access publication under the terms and (c) (i) conditions of the Creative Commons Attribution (CC BY) license (http://creativecommons.org/licenses/by/4.0/). 